\title{
Sustained Low Incidence Rates of Central Line-Associated Blood Stream Infections in the Intensive Care Unit
}

This article was published in the following Dove Press journal: Infection and Drug Resistance

\author{
Waleed A Mazi' \\ Mohammed H Abdulwahab' \\ Mahmood A Alashqar' \\ Yvonne S Aldecoa' \\ Zaheda R Bahat' \\ Jennifer L Suaking' \\ Amir Saeed ${ }^{2,3}$ \\ Osama $S$ Yassin ${ }^{4}$ \\ Salah AI-Din Mahfouz ${ }^{5}$ \\ Abiola Senok (DD ${ }^{6}$ \\ 'Infection Prevention and Control, King \\ Faisal Medical Complex, Taif, Kingdom of \\ Saudi Arabia; ${ }^{2}$ Department of Laboratory \\ Sciences, College of Applied Medical \\ Sciences, University of Hail, Hail, \\ Kingdom of Saudi Arabia; ${ }^{3}$ Department of \\ Medical Microbiology, Faculty of Medical \\ Laboratory Sciences, University of \\ Medical Sciences \& Technology, \\ Khartoum, Sudan; ${ }^{4}$ Intensive Care Unit, \\ King Faisal Medical Complex, Taif, \\ Kingdom of Saudi Arabia; ${ }^{5}$ Surgeon and \\ Head of Endoscopy, King Faisal Medical \\ Complex, Taif, Kingdom of Saudi Arabia; \\ ${ }^{6}$ College of Medicine, Mohammed Bin \\ Rashid University of Medicine and Health \\ Sciences, Dubai, United Arab Emirates
}

Correspondence: Waleed A Mazi Infection Prevention and Control, King Faisal Medical Complex-Taif, P.O. Box: 9970, Taif, 21944, Kingdom of Saudi Arabia

Tel +966504722440

Email waleedmazi@yahoo.com
Background: Central line-associated bloodstream infection (CLABSI) is an important cause of increased morbidity and mortality in ICUs. The occurrence of CLABSI in significantly higher in developing countries and contributes to the burden of healthcare-associated infections.

Methods: This prospective study was carried out from January 2016 to December 2019 in the intensive care unit at King Faisal Medical Complex in Taif, Saudi Arabia. The Society for Healthcare Epidemiology of America/Infectious Diseases Society of America (SHEA/IDSA) recommendations were introduced and implemented during 2017-2019. In the postintervention period, observation of hand hygiene, CLABSI bundle compliance, and benchmarking of CLABSI rates were carried out.

Results: The CLABSI incidence rate was $1.12 / 1,000$ central-line days, with a 0.51 utilization ratio in the pre-intervention period. This dropped to $0.46 / 1,000$ central line days with a 0.44 utilization ratio in the post-intervention period. This reduction was also confirmed in benchmarking with National Healthcare Safety Network (NHSN) (50th-75th) percentile preintervention vs (25th-50th) percentile post-intervention. Institutional risk assessment revealed a formal educational program as a potential need for improvement. The CLABSIs were caused predominantly by multidrug-resistant Klebsiella pneumoniae.

Conclusion: We observed a reduction and sustained low incidence rate of CLABSI benchmarking to NHSN for 3 years after implementation of the basic SHEA/IDSA recommendations.

Keywords: central line-associated bloodstream infection, SHEA/IDSA, healthcareassociated infections, Saudi Arabia

\section{Background}

Healthcare associated infections (HAIs) represent a global health challenge and there is a need to establish effective infection prevention and control strategies. HAIs increase mortality, length of hospital stay, cost of care, bacterial resistance, antibiotic use, etc in intensive care units (ICUs), particularly in developing countries. $^{1,2}$ The International Nosocomial Infection Control Consortium showed that the incidence rate for central line-associated bloodstream infection (CLABSI) in ICUs in developing countries was 3-fold higher than in the United States of America. ${ }^{3}$ The implementation of a prevention CLABSI bundle can significantly reduce the occurrence of HAIs. ${ }^{4-7}$ Mazi et $\mathrm{al}^{8}$ have previously demonstrated that the utilization of the Society for Healthcare Epidemiology of America and the 
Infectious Diseases Society of America (SHEA/ISDA) basic practice recommendation resulted in reduction in the incidence of CLABSI rates in an acute trauma ICU. For further investigation of the impact of the SHEA/IDSA CLABSI prevention model in our setting, the utilization of the model was expanded to the medical-surgical ICU of another tertiary care facility and the effectiveness in CLABSI reduction was prospectively studied.

\section{Methods}

This prospective study was conducted from January 2017 December 2019 at the 27-bed medical-surgical ICU of King Faisal Medical Complex in Taif, Saudi Arabia. King Faisal Medical Complex is an 800-bed referral teaching hospital with a catchment population of approximately 2 million people.

\section{Bacterial Identification and Determination of CLABSI}

Bacterial identification and antimicrobial susceptibility of isolates were determined according to Clinical Laboratory Standards Institute guidelines.9 Laboratory-confirmed CLABSI was identified using the Centers for Disease Control and Prevention and National Healthcare Safety Network (NHSN; formerly the National Nosocomial Infection Surveillance System) criteria. $^{10}$ In brief, CLABSI is defined as a laboratory confirmed bloodstream infection in a patient with a central line placed for more than 2 calendar days prior to a positive culture. Statistical analysis including calculation of incidence rate, ratio and benchmarking was carried out in accordance with NHSN recommendations. The formula calculation of CLABSI incidence rate is the number of CLABSI divided by central line days multiplied by 1,000 . The utilization ratio is the number of central line days divided by patients' days. ${ }^{11}$

\section{Implementation of SHEA/IDSA Guidelines} In the pre-intervention period (2016), there was no CLABSI prevention team in the hospital and baseline risk assessment as well as formal educational activity had not been performed. During this pre-intervention period, the hospital was implementing the basic CLABSI bundle program, which included hand hygiene, maximal barrier precautions, chlorohexidine skin antisepsis, and daily review of central lines with prompt removal of unnecessary lines. The infection rates were also regularly monitored.
In January 2017, preventive measures using basic SHEA/IDSA practice recommendations were introduced. ${ }^{12}$ With the introduction of the SHEA/IDSA guidelines, several measures were instituted in the facility. This included having a CLABSI prevention team which comprised of the head of infection control, an infectious diseases physician, an intensive care consultant, an intensive care link nurse, and an Infection Preventionist. Secondly, a baseline risk assessment was performed in January 2017 using the Wirral Primary Care Trust tool, ${ }^{13}$ and practices which were not in compliance with the SHEA/IDSA basic recommendation were identified as a CLABSI risk factor. The only identified risk factor was the absence of an in-house continuing education program, and an action plan to address this was developed, approved, and implemented in February 2017. The risk was resolved in February 2017 with the delivery of a fullday formal educational program on CLABSI prevention measures which was collaboratively organized by a team comprising of ICU physicians and nurses, microbiologists, and staff from the infection control as well as the quality and patient safety departments. The educational program included oral presentations addressing various topics including clinical manifestations and complications of bloodstream infections, indicators and benchmarking guidelines, SHEA/IDSA practice recommendations, and guidelines for optimal blood cultures. There was an open discussion forum as well as a practical exercises workshop. The SHEA/IDSA guidelines were fully implemented from March 2017-December 2019, and prospective evaluation of hand hygiene compliance and CLABSI rates were carried out during this post-intervention period. The observations for hand hygiene compliance were carried out by trained infection preventionists using the World Health Organization My five Moments for Hand Hygiene recommendations. ${ }^{14}$ The CLABSI prevention bundle program was monitored using Institute for Healthcare Improvement guidelines. ${ }^{15}$ Regular meetings and feedback for stakeholders and hospital management were implemented and documented. External validation surveillance was conducted by reviewing all blood culture results in patients with a central line device and case definition of CLABSI. ${ }^{16}$

\section{Monitoring Compliance of Hand Hygiene}

The trained members of Infection Preventionists using the WHO Hand Hygiene Observation Form carried out the hand hygiene compliance rates. ${ }^{14}$ 


\section{Monitoring Compliance of CLABSI \\ Bundle}

CLABSI Bundle compliance rates were assessed using Institute for Healthcare Improvement (IHI) guidelines. The bundle component included the following; hand hygiene; maximal barrier precautions; chlorhexidine skin antisepsis; optimal catheter site selection, and daily review of line necessity, with prompt removal of unnecessary lines. ${ }^{17}$

\section{Results}

Institutional risk assessment revealed a formal educational program as an area that needed improvement. During the study period, the total number of reported CLABSI cases was 15 , which represented an overall incidence rate $0.63 / 1,000$ central-line days and a utilization ratio of 0.45 . Specifically, for the preintervention phase, the CLABSI incidence rate was $1.12 / 1,000$ central-line days with a 0.51 utilization ratio, representing 50-75 and 50 percentile benchmarking to NHSN, respectively. The post-intervention incidence rate of CLABSI was $0.46 / 1,000$ central line days with a 0.44 utilization ratio representing $25-50$ percentile benchmarking to NHSN (Table 1). The patients with CLABSI ranged from $13-83$ years in age (mean $\pm \mathrm{SD}=51$ \pm 26.5 years). All patients had subclavian vein as the site of catheter insertion. The interval between insertion of the central line and diagnosis of CLASBI ranged from 7-26 days (mean $\pm \mathrm{SD}=14 \pm 7.6$ days). Indication for ICU admission were respiratory illnesses, including pleural effusion and pneumonia, trauma with head injury and seizures.

The hand hygiene compliance rate was not constant and ranged between 75 in 2016 to 80 in 2018. The
CLABSI bundle compliance rate was $100 \%$ for most of the bundle's components from 2017 to 2019 (Table 2).

The CLASBIs were caused predominantly by multidrug resistant bacteria, namely extended spectrum beta-lactam (ESBL) and carbapenem resistant Klebsiella pneumoniae, multi-drug resistance (MDR) Pseudomonas aeruginosa, Proteus mirabilis, and Acinetobacter baumanii (Table 3). No outbreak was observed during the study period. Observation of hand hygiene compliance revealed that the compliance rate ranged from $70-80 \%$, and the alcohol hand rub consumption rate was sustained at $50 \%$ during the study period.

\section{Discussion}

CLABSI is an important cause of increased morbidity and mortality, as well as a contributory factor to increased length of hospitalization and healthcare costs in ICUs. In the Kingdom of Saudi Arabia, CLABSI constitutes $14-38.5 \%$ of healthcare device associated infections, with incidence rates ranging from 2.2-29.7 per 1,000 central-line days in ICUs during 2011-2018. ${ }^{18-20}$ The CLABSI incidence rate to percentile NHSN benchmarking for 2016 in the study center indicated the need to improve patient care practice in the ICU. Mazi et $\mathrm{al}^{8}$ had previously demonstrated significant CLABSI reduction (58\%) in the ICU after implementation of SHEA/ISDA practice recommendations in another tertiary care facility in Saudi Arabia. Therefore, a strategic plan to reduce CLABSI and deliver high quality performance and patient safety via introduction of the SHEA/IDSA as a prevention model in the medical-surgical ICU was instituted. In addition, the basic SHEA/ISDA practice recommendations were written in concise format and with applicability in our setting, with measurable elements.

Table I Incidence Rate and Ratio of CLABSI Reported During Pre- and Post-Intervention at the Study Hospital Compared with NHSN Hospitals, DA Module 2013

\begin{tabular}{|c|c|c|c|c|c|c|c|c|c|}
\hline \multirow[t]{2}{*}{ Intervention/Year } & \multirow[t]{2}{*}{$\begin{array}{l}\text { No. of } \\
\text { HAls }\end{array}$} & \multirow[t]{2}{*}{$\begin{array}{c}\text { Device- } \\
\text { Days }\end{array}$} & \multirow[t]{2}{*}{$\begin{array}{c}\text { Patient- } \\
\text { Days }\end{array}$} & \multirow{2}{*}{$\begin{array}{c}\text { Incidence } \\
\text { Ratel } \\
\text { I,000 } \\
\text { Device- } \\
\text { Days }\end{array}$} & \multicolumn{2}{|c|}{$\begin{array}{l}\text { Benchmarking to } \\
\text { NHSN-20I5 }\end{array}$} & \multirow[t]{2}{*}{$\begin{array}{c}\text { Utilization } \\
\text { Ratio }\end{array}$} & \multicolumn{2}{|c|}{$\begin{array}{l}\text { Benchmarking to } \\
\text { NHSN-20I5 }\end{array}$} \\
\hline & & & & & $\begin{array}{c}\text { Pooled } \\
\text { Mean }\end{array}$ & Percentile & & $\begin{array}{l}\text { Pooled } \\
\text { Mean }\end{array}$ & Percentile \\
\hline Pre-intervention/2016 & 7 & 6,218 & 12,155 & 1.12 & 0.8 & $50-75 \%$ & $0.5 I$ & 0.49 & $50 \%$ \\
\hline $\begin{array}{l}\text { Post- } \\
\text { intervention/2017-2019 }\end{array}$ & 8 & 17,377 & 39,471 & 0.46 & 0.8 & $25-50 \%$ & 0.44 & 0.49 & $25-50 \%$ \\
\hline
\end{tabular}

Abbreviations: CLASBI, central line-associated bloodstream infection; DA, device associated; NHSN, National Healthcare Safety Network-USA. 
Table 2 CLABSI Bundle Compliance Rate After Intervention Period 2017-2019

\begin{tabular}{|c|c|c|c|c|c|c|c|c|c|}
\hline \multirow[t]{2}{*}{ Bundle Components } & \multicolumn{3}{|c|}{$2017 *$} & \multicolumn{3}{|c|}{2018} & \multicolumn{3}{|c|}{2019} \\
\hline & Opportunity & Action & Rate \% & Opportunity & Action & Rate \% & Opportunity & Action & Rate $\%$ \\
\hline Hand hygiene & 546 & 546 & 100 & 1,643 & $\mathrm{I}, 643$ & 100 & $\mathrm{I}, 587$ & $\mathrm{I}, 587$ & 100 \\
\hline $\begin{array}{l}\text { Maximal barrier } \\
\text { precautions }\end{array}$ & 546 & 546 & 100 & $\mathrm{I}, 643$ & 1,643 & 100 & $\mathrm{I}, 587$ & $\mathrm{I}, 587$ & 100 \\
\hline $\begin{array}{l}\text { Chlorohexidine skin } \\
\text { antisepsis }\end{array}$ & 546 & 546 & 100 & 1,643 & $\mathrm{I}, 643$ & 100 & I,587 & $\mathrm{I}, 587$ & 100 \\
\hline $\begin{array}{l}\text { Optimal catheter site } \\
\text { selection }\end{array}$ & 546 & 546 & 100 & 1,643 & $\mathrm{I}, 643$ & 100 & $\mathrm{I}, 587$ & $\mathrm{I}, 587$ & 100 \\
\hline $\begin{array}{l}\text { Daily review of line } \\
\text { necessity }\end{array}$ & 546 & 544 & 99.63 & 1,643 & $\mathrm{I}, 642$ & 99.94 & $\mathrm{I}, 587$ & $\mathrm{I}, 555$ & 97.98 \\
\hline
\end{tabular}

Note: *Data is only from June to December 2017.

Device-associated infection rates and device utilization ratios should be examined together to ensure appropriate targeting of CLABSI preventive measures. ${ }^{11,21}$ An incidence CLABSI rate in the 75th percentile with a utilization ratio at 50th percentile of NHSN benchmarking indicates the prevention measures should be focused on the practices before and during insertion of the central line. In the post-intervention period, the CLABSI incidence rate and device utilization ratio declined and were maintained at levels below the mean of the NHSN percentile (25th-50th), confirming that provision of an educational program was an important prevention measures in our setting. The lack of familiarity with practice guidelines by healthcare workers has been identified as a main barrier in the proper implementation of these guidelines. Perez Parra et $\mathrm{al}^{21}$ observed a significant reduction (35\%) of CLABSI in ICUs after education interventions, and

Table 3 Number of Microorganisms Causing CLABSIs During the Study Period

\begin{tabular}{|l|c|c|c|c|}
\hline \multirow{2}{*}{ Microorganism } & \multicolumn{4}{|c|}{ Number of Isolates per Year } \\
\cline { 2 - 5 } & $\mathbf{2 0 1 6}$ & $\mathbf{2 0 1 7}$ & $\mathbf{2 0 1 8}$ & $\mathbf{2 0 1 9}$ \\
\hline Klebsiella pneumonia & 7 & 0 & 2 & 1 \\
\hline Acinetobacter baumanii & 0 & 0 & $\mathrm{I}$ & 0 \\
\hline Proteus mirabilis & 0 & 0 & 0 & $\mathrm{I}$ \\
\hline Pseudomonas areuginosa & 0 & $\mathrm{I}$ & 0 & $\mathrm{I}$ \\
\hline Enterococcus faecalis & 0 & 0 & $\mathrm{I}$ & 0 \\
\hline
\end{tabular}

Abbreviation: CLASBI, central line-associated bloodstream infection. noted that an updated educational program is the first step toward achieving adherence to guidelines. Validation is an important step toward assuring for action and motivates infection control efforts rather than strategies to avoid accounting for HAIs. Official external validation can help assure adherence to Ministry of Health $(\mathrm{MOH})$ guidelines specifications for CLABSI reporting. ${ }^{16}$ The external validation report showed full agreement in data surveillance results between the hospital data and the agency. Members of the external agency of the regional directorate for infection prevention and control were authorized from the local ministry of health, are welltrained, and have good experience in hospital infection control surveillance.

Regular meetings with the CLABSI prevention team and ICU department were held with dissemination of feedback to all stakeholders. However, despite regular reminders about the importance of hand hygiene, the compliance rates were variable $(70-80 \%$; average rate $=73 \%)$, with low alcohol hand rub consumption rates. This is probably because the ICU is a very busy care area, but it also signifies an important area for future improvement.

Several scientific-based evidence demonstrated an association between hand hygiene compliance and healthcare associated infections. Rosenthal et $\mathrm{al}^{22}$ conducted an observational, prospective cohort and intervention with multidimensional hand hygiene approach studies in 99 ICUs of 65 International Nosocomial Infection Control Consortium (INICC) member hospitals from 51 cities of 19 limited-resource countries for 13 years. The study included six measures: 1) administrative support, 2) 
supplies availability, 3) education and training, 4) reminders in the workplace, 5) process surveillance, and 6) performance feedback. The hand hygiene compliance rate was increased from $48.3 \%$ to $71.4 \%$ and consequently reduced the rate of CLABSI by $54 \%$, of by $37 \%$, and of VAP by $56 \%$. However, hand hygiene alone cannot influence other risk factors, such as older age, immunosuppression, admission to the intensive care unit, the longer length of stay, and indwelling devices and possible resulting to potential confounders, such as surveillance methodology, local antibiotic prescribing, nurse-to-patient-ratio, screening multi-drug resistance organisms, environmental cleaning regimen, and implementation to a bundle program. ${ }^{23}$

Care "bundles" are simple sets of evidence-based practices (three-to-five components) to improve the reliability of their delivery and improve patient care when implemented together. The Institute for Healthcare Improvement (IHI) developed the concept of "bundles" to help healthcare providers for the best possible patient care. Care bundles were proposed to ensure that all patients consistently receive the best care or treatment at all times. The hospital introduced the CLABSI bundle compliance by the middle of 2017; therefore, we do not have the bundle compliance rate from 2016 up to May 2017. Results showed a significant reduction of CLABSI incidence rate after implementation of the CLABSI bundle program. Similarly, many hospitals showed a positive impact on the reduction of HCAI after implemented the bundle program. Fang et $\mathrm{al}^{24}$ observed decreased hospital deviceassociated infection after introducing the bundle program with a compliance rate of about $91 \%$. The reduction was accompanied by a decrease in the utilization of invasive devices. Although there was diversity in the ages and indication for admission in our patients, all had the subclavian vein as the site of central line insertion. This is in keeping with the $\mathrm{CDC}$ recommendation of the subclavian vein as a first choice for central line insertion.

Nevertheless, the significant reduction in CLABSI in our ICU indicates a positive impact of addressing bundle compliance. In addition, a provision of an educational program for the healthcare workers, use of a catheter cart, and regular feedback of hand hygiene and bundle compliance rate to all stakeholders assumed played effective strategies to reduce CLABSI incidence rate in the ICU, as recommended by SHEA/IDSA. As a limitation of this work, we could not specify which risk factor was responsible for the significant reduction observed.

\section{Conclusion}

We observed a sustained reduction with low incidence rate of CLABSI benchmarking to NHSN after implementation of the basic SHEA/IDSA practice recommendation. Therefore, the basic SHEA/ISDA practice recommendation is an effective prevention model for the reduction of CLABSI in the ICU.

\section{Abbreviations}

CPR, carbapenem resistance; CLABSI, central lineassociated bloodstream infection; ESBL, extended spectrum beta-lactam; HAI, Healthcare associated infection; ICU, Intensive Care Unit; IDSA, Infectious Diseases Society of America; MDR, multi-drug resistance; $\mathrm{MOH}$, Ministry of Health; NHSN, National Healthcare Safety Network, USA, SHEA, Society Healthcare Epidemiology of America.

\section{Data Sharing Statement}

All data and materials are available from Waleed A. Mazi and most welcome for providing, when needed.

\section{Ethical Considerations and Publications}

The ethical committee of the Ministry of Health of the Kingdom of Saudi Arabia has approved the research under the approval reference number 380 . There is no objection for publication. All coauthors participated to the research and agreed to publication. The document has been submitted.

\section{Acknowledgment}

We would like to thank the Regional Directorate for Infection Prevention and Control for conducting blinding validation surveillance, especially Dr. Masood Ahmad Shah, who is an expert in the hospital infection prevention and control program. The project was presented in part as a poster presentation at the 5th International Conference of Prevention and Infection Control, Geneva, Switzerland, September 10-13, 2019.

\section{Author Contributions}

All authors made a significant contribution to the research reported, whether that is in the conception, study design, execution, acquisition of data, analysis and interpretation, or in all these areas; took part in drafting, revising, or critically reviewing the article; gave final approval of the version to be published; have agreed on the journal to 
which the article has been submitted; and agree to be accountable for all aspects of the research work.

\section{Disclosure}

The authors report no conflicts of interest in this work.

\section{References}

1. Centers for Disease, C. and Prevention. Monitoring hospital-acquired infections to promote patient safety-United States, 1990-1999. MMWR Morb Mortal Wkly Rep. 2000;49(8):149-153.

2. Siddiqui S, Saeed M, Faisal SM, et al. Molecular and phenotypic characterization of the vancomycin-resistant gene in bacterial isolates acquired from catheter tips. Cell Mol Biol (Noisy-Le-Grand). 2017;63 (12):63-67. doi:10.14715/cmb/2017.63.12.14

3. Rosenthal VD, Bijie H, Maki DG, et al. International Nosocomial Infection Control Consortium (INICC) report, data summary of 36 countries, for 2004-2009. Am J Infect Control. 2012;40(5):396-407. doi:10.1016/j.ajic.2011.05.020

4. Prakash SS, Rajshekar D, Cherian A, et al. Care bundle approach to reduce device-associated infections in a tertiary care teaching hospital, South India. J Lab Physicians. 2017;9(4):273. doi:10.4103/JLP. JLP_162_16

5. Pogorzelska M, Stone PW, Furuya EY, et al. Impact of the ventilator bundle on ventilator-associated pneumonia in intensive care unit. Int J Qual Health Care. 2011;23(5):538-544. doi:10.1093/intqhe/ mzr049

6. Menegueti MG, Ardison KMM, Bellissimo-Rodrigues F, et al. The impact of implementation of bundle to reduce catheter-related bloodstream infection rates. J Clin Med Res. 2015;7(11):857-861. doi:10.14740/jocmr2314w

7. Crolla RMPH, van der Laan L, Veen EJ, et al. Reduction of surgical site infections after implementation of a bundle of care. PLoS One. 2012;7(9):e44599. doi:10.1371/journal.pone.0044599

8. Mazi W, Begum Z, Abdulla D, et al. Central line-associated bloodstream infection in a trauma intensive care unit: impact of implementation of society for healthcare epidemiology of America/Infectious Diseases Society of America practice guidelines. Am J Infect Control. 2014;42(8):865-867. doi:10.1016/j.ajic.2014.05.005

9. Wayne P. Clinical and laboratory standards institute: performance standards for antimicrobial susceptibility testing: 20th informational supplement. CLSI document M100-S20; 2010.

10. Horan TC, Andrus M, Dudeck MA, et al. CDC/NHSN surveillance definition of health care-associated infection and criteria for specific types of infections in the acute care setting. Am J Infect Control. 2008;36(5):309-332. doi:10.1016/j.ajic.2008.03.002

11. Dudeck MA, Horan TC, Peterson KD, et al. National Healthcare Safety Network (NHSN) report, data summary for 2010, device-associated module. Am J Infect Control. 2011;39(10):798-816. doi:10.1016/j. ajic.2011.10.001

Infection and Drug Resistance

\section{Publish your work in this journal}

Infection and Drug Resistance is an international, peer-reviewed openaccess journal that focuses on the optimal treatment of infection (bacterial, fungal and viral) and the development and institution of preventive strategies to minimize the development and spread of resistance. The journal is specifically concerned with the epidemiology of
12. Marschall J, Mermel LA, Classen D, et al. Strategies to prevent central line-associated bloodstream infections in acute care hospitals. Infect Control Hosp Epidemiol. 2008;29(Suppl S1):S22-S30. doi:10.1086/591059

13. Officer NR, et al. Wirral primary care trust infection prevention and control strategy 2008-2011. Policy. 2008.

14. Sax H, Allegranzi B, Chraiti M-N, et al. The World Health Organization hand hygiene observation method. Am $J$ Infect Control. 2009;37(10):827-834. doi:10.1016/j.ajic.2009.07.003

15. bundle., I.f.H.I.I.t.c.l. Available from: http://www.ihi.org/resources/ Pages/Changes/ImplementtheCentralLineBundle.aspx. Accessed April 1, 2009.

16. Toolkit, N.H.S.N.N.E.V.G.a. 2017. Available from: https://www.cdc. gov/nhsn/pdfs/validation/2017/2017-nhsn-ev-guidance.pdf. Accessed February 16, 2021.

17. Available from: http://www.ihi.org/Topics/CentralLineInfection/ Pages/default.aspx. Accessed February 16, 2021.

18. Al-Abdullah N. Epidemiology of Central Line-Associated Bloodstream Infection (CLABSI) among patients in the Intensive Care Units (ICUs) at a teaching hospital in Saudi Arabia from year 2011-2016. J Intensive Crit Care. 2018;4(1):2.

19. Gaid E, Assiri A, McNabb S, et al. Device-associated nosocomial infection in general hospitals, Kingdom of Saudi Arabia, 2013-2016. J Epidemiol Glob Health. 2017;7(Suppl S1):S35-S40. doi:10.1016/j. jegh.2017.10.008

20. Khan RM, Subhani J, Arabi Y, et al. Central line-associated bloodstream infections in the Kingdom of Saudi Arabia. Saudi Crit Care J. 2019;3(1):43. doi:10.4103/2543-1854.259482

21. Perez Parra A, Menárguez MC, Granda MJP, et al. A simple educational intervention to decrease incidence of Central Line-Associated Bloodstream Infection (CLABSI) in intensive care units with low baseline incidence of CLABSI. Infect Control Hosp Epidemiol. 2010;31(9):964-967. doi:10.1086/655841

22. Rosenthal VD, Pawar M, Leblebicioglu H, et al. Impact of the International Nosocomial Infection Control Consortium (INICC) multidimensional hand hygiene approach over 13 years in 51 cities of 19 limited-resource countries from Latin America, Asia, the Middle East, and Europe. Infect Control Hosp Epidemiol. 2013;34 (4):415-423. doi:10.1086/669860

23. McLaws M-L. The relationship between hand hygiene and health care-associated infection: it's complicated. Infect Drug Resist. 2015;8:7-18. doi:10.2147/IDR.S62704

24. Gao F, Wu -Y-Y, Zou J-N, et al. Impact of a bundle on prevention and control of healthcare associated infections in intensive care unit. J Huazhong Univ Sci Technolog Med Sci. 2015;35(2):283-290. doi:10.1007/s11596-015-1425-2

antibiotic resistance and the mechanisms of resistance development and diffusion in both hospitals and the community. The manuscript management system is completely online and includes a very quick and fair peerreview system, which is all easy to use. Visit http://www.dovepress.com/ testimonials.php to read real quotes from published authors. 